\title{
Hybrid islanding detection method based on the rate of change of frequency and load impedance
}

\author{
Hasmaini Mohamad, Zuhaila Mat Yasin, Nur Ashida Salim, Bibi Norasiqin Sheikh Rahimullah, \\ Kanendra Naidu \\ School of Electrical Engineering, College of Engineering, Universiti Teknologi MARA, 40450 Shah Alam, Selangor, \\ Malaysia
}

\section{Article Info}

Article history:

Received Jun 7, 2021

Revised Aug 24, 2021

Accepted Oct 8, 2021

\section{Keywords:}

Distributed generation

Islanding detection

Load impedance

Rate of change of frequency

\begin{abstract}
Interconnection of distributed generation (DG) in distribution system will result in formation of islands in the event of loss of main supply. This scenario is harmful to the power system, hence quick detection is critical to halt the formation of islands. Among the common passive and active detection methods available, the hybrid detection method is identified as the most reliable method. This paper proposes a new hybrid method using the combination of passive and active technique which is the rate of change of frequency (ROCOF) and load impedance, respectively. The passive method works when the value of ROCOF exceeds the threshold value which is set at $0.3 \mathrm{~Hz} / \mathrm{s}$. The active method works when it detects low value of ROCOF and immediately inject a pre-specified load into the system to increase the ROCOF value up to its threshold value. Simulation study on different case studies is carried out on distribution test system to evaluate the performance of the proposed method. Results show that this method is effective in detecting any events that could result in islanding.
\end{abstract}

This is an open access article under the CC BY-SA license.

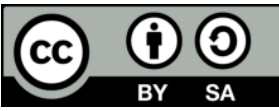

Corresponding Author:

Hasmaini Mohamad

School of Electrical Engineering, College of Engineering

Universiti Teknologi MARA, Shah Alam, Selangor, Malaysia

Email: hasmaini@uitm.edu.my

\section{INTRODUCTION}

Distributed generation (DG) is a small-scale power generation technology installed in the vicinity of the end users in order to produce electricity. DGs cover any net metered or commercial-scale generation that is connected to the grid at the distribution level. DGs are important as they offer many benefits to the power system such as enhancing the efficiency of electricity supply, reducing distribution and transmission losses and delivering clean and sustainable power to the customers. However, there is a technical issue called islanding which occurs when DG continues supplying power to a part of the distribution system eventhough the connection to the grid is interrupted during catastrophic event.

Islanding can be either intentional or unintentional islanding. Intentional islanding is a properly planned process to improve the system reliability where DG continuously supply power to critical loads in the event of power supply failure from the grid. Readiness of an advanced control scheme in ensuring a smooth changes from grid connected to islanding mode of operation is required. With the controller in place, the grid can sectionalize itself by allowing the DG to supply the islands' load until the main power supply is re-established. On the other hand, unintentional islanding may result in damaging the DG since it operates without proper control mechanism for islanding [1]. Similarly, this is hazardous for utility workers working in the distribution system who are unaware that the network is still operational. This situation usually occurs 
when the power is being fed via the DG to the system during loss of main supply form the grid . The exposure to live system can be fatal to the utility workers [2]. Therefore, DG's protection scheme has to detect the islanding situation and immediately disconnect DG from the network. This is referred to as islanding detection method.

Islanding detection methods for both intentional and unintentional islanding are generally classified into local and remote methods. Local method can be further categorized into active and passive methods while remote method is based on communication between the utility and the DGs [3]. Passive method identifies islanding by monitoring the parameters such as frequency, voltage, current, active power, reactive power and harmonic distortion. Many techniques were subsequently introduced with various combination of parameters and settings such as rate of change of positive and negative sequence component [4], rate of change of frequency (ROCOF) [5], rate of change of output power [6], rate of change of voltage and changes in power factors [7], voltage unbalance and total harmonic distortion of current [8] and combinations of four passive parameters [9]. The very recent research considered load angle and mechanical power parameters [10], undervoltage block function [11] and sensitivity of different passive parameters [12]. When the distribution system is islanded, these parameters are significantly affected. Detection relies on the threshold setting for each parameter which will discriminate islanding and non-islanding type of disturbance. However, islanding is difficult to detect when there is minimal power mismatch between generation and load in the islanded system. If the threshold values is too high, islanding might not be detected while if the threshold values is too low, it could result in false tripping of DG.

The weakness of the passive method can be complemented by active method, which can detect the occurrences of islanding even under zero power imbalance between generation and load. Active method identifies a grid failure or islanding by injecting a small signal into the system. This method is applicable for inverter based DGs. Methods such as active positive feedback islanding detection schemes [13], DC/AC inverter acting as virtual capacitor [14], frequency dependent ZIP-Exponential static load model [15], impedance-based analysis of the active frequency drift (AFD) [16], d-axis current injection [17], islanding detection index based on resistance seen from the SSSG terminal with respect to the angular frequency [18] and high-frequency signal injection for multiple parallel-connected inverters based DG [19]. These methods outperforms the passive method but are rather expensive and pose power quality deterioration.

The recent trend of islanding detection using intelligent based and hybrid methods where both associated with passive and/or active method. Intelligent method is based on the application of artificial neural network (ANN), fuzzy logic control (FLC), evolutionary programming (EP), decision tree (DT) [20], adaptive neuro fuzzy inference system (ANFIS) [21], and support vector machine (SVM) [22]. These methods help to classify islanding/non islanding events based on training and testing data obtained from the simulation/experiment conducted on the test system. Testing on different types of faults based on passive parameter is rigorously carried out to generate huge amount of data. As a result, the classification is accurate with a nearly zero non-detection zone (NDZ) and detection is reached in a very short time. However, any changes made on the test system such as network expansion, will cause the need of a new set training data for classification process.

Introduction of hybrid islanding detection method [23] can overcome the shortcomings in passive or active method approach. It combines the advantages of both method to offer more effective result compared to passive/active method alone. Hybrid method proposed in the literatures considered combination of voltage unbalance and frequency set point [24], average rate of voltage change and real power shift [25], voltage unbalance (VU) and high-frequency (HF) impedance [26], dynamic characteristics of synchronous generator and signal processing technique [27], voltage unbalance and total harmonic distortion (VU/THD) and bilateral reactive power variation (BRPV) [28], rate of change of exciter voltage (RCEV) and open-close circuit breaker (OCCB) at a DG connection point [29]. In addition, there is also a new approach of hybrid method using combination of active, passive and communication technique [30]. Each method has different detection performance depending on the chosen combination. The active technique is normally adopted when passive technique alone is unable to detect islanding scenario particularly during minimal power mismatch. So far, the hybrid method employs the combination of a new type of passive method with an advanced active method. However, the research work on hybrid method using the ROCOF which is commonly adopted by utility companies has not been explored in detail. This is important as a comprehensive investigation is required on the practicality of applying proposed hybrid method to existing islanding detection technique.

This paper proposes a new hybrid method which combines ROCOF as the passive method and injection of load impedance as the active method. ROCOF is chosen since it is commonly used as the main protection system in distribution system. ROCOF operates when it detects islanding based on the rate of changes of frequency that exceeds the threshold limit. The load impedance is injected to the system when it detects a small value of ROCOF. The injection will increase the value of ROCOF up to the specified limit. This will ensure that the islanding detection is successful even there is a small power mismatch. The main 
contributions of this studies are: 1) quick islanding detection which is less than 20ms, 2) effective detection of islanding and non-islanding event, and 3) employs a simple method using standard parameter measurement. This method is modelled and simulated using PSCAD/EMTDC simulation tools. In order to evaluate this method, there are seven case studies introduced which are loss of main, fault at adjacent line (single line to ground fault, line to line to ground fault, and three phase fault) and fault near to DG (single line to ground fault, line to line to ground fault, and three phase fault). This paper is organized as follows in which the proposed hybrid detection method and test system are elaborated in section 2, result and discussion are explained in section 3 and finally conclusion is drawn in section 4.

\section{RESEARCH METHOD}

The hybrid islanding detection method applied in this study uses ROCOF as a passive method and the injection of load impedance as the active method. The modelling of the proposed method and test system are described in the following section.

\subsection{Modeling proposed method}

Two modules comprising of active and passive method are developed for the proposed hybrid method as depicted in Figure 1. Passive and active module are located in the DG protection unit and at the generator bus, respectively.

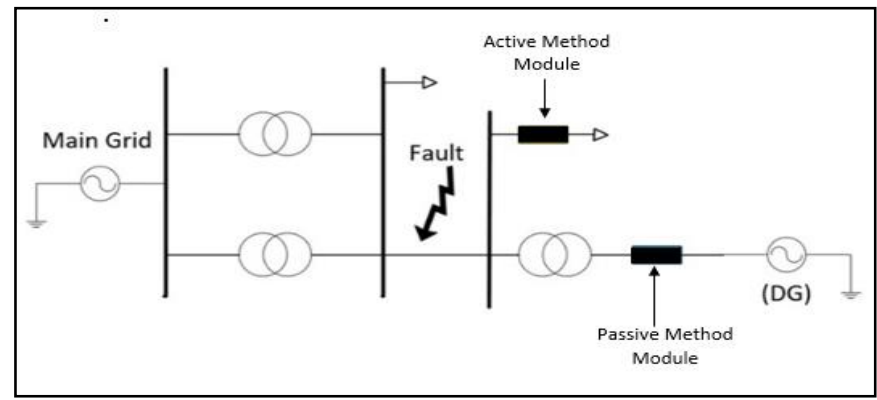

Figure 1. Principal operation of the proposed method

The development concept of the hybrid method is shown in Figure 2. The passive method module is used to continuously monitor the ROCOF value which is taken from the speed measurement of DG. The proposed method detects any islanding event whenever the ROCOF value exceeds the specified threshold. A tripping signal is subsequently sent to circuit breaker of the DG's protection system thus prohibiting the DG from supplying the load. Active method module will only be activated to inject an additional load to the system whenever it detects ROCOF value less than the threshold value. Details of the islanding detection process is described in Figure 3.

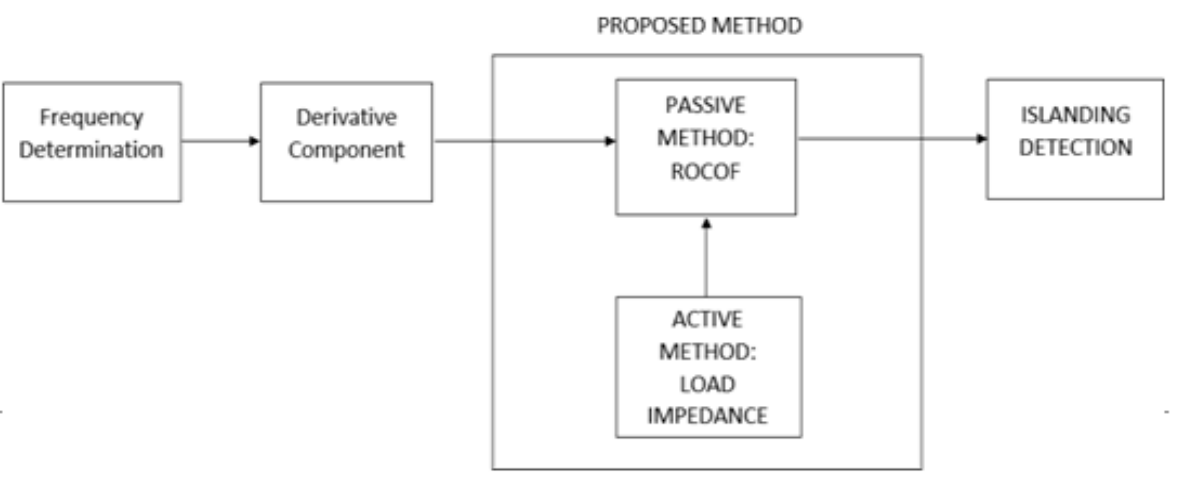

Figure 2. Block diagram of the proposed method 
The process starts with the determination of frequency from the speed measurement of DG. Then, derivative component is used to calculate the rate of change of frequency (ROCOF). The active and passive method are designed specifically for detection purposes considering the ROCOF as the input. The script for designing the module is written using FORTRAN programming language. The passive module is designed based on the comparison between the calculated ROCOF value and ROCOF threshold setting. Detection module will be triggered once the ROCOF value surpass the threshold value. The common setting for ROCOF threshold is between $0.1 \mathrm{~Hz} / \mathrm{s}$ to $1 \mathrm{~Hz} / \mathrm{s}$ [12]. In this study, the threshold value of $0.3 \mathrm{~Hz} / \mathrm{s}$ is used. Meanwhile, the output of the active method module will send a signal to inject a load with a value of $330 \mathrm{~kW}$ to the system when the magnitude of the calculated ROCOF is less than $0.3 \mathrm{~Hz} / \mathrm{s}$. The value of the injected load cannot be too high because it will cause system interference. The value of $330 \mathrm{~kW}$ is deemed suitable for the system is determined from several tests conducted for LOM as recorded in Table 1. The value of active load highly depends on the power imbalance the moment system experiences disturbance. Lower power imbalance of less than $270 \mathrm{MW}$, would require an injection of a large load value of 540kW. High value of load is infeasible for islanding detection purposes as it would incur high cost. The load injection for power imbalance greater than $280 \mathrm{MW}$ would result in a steep increase of ROCOF value to more than $0.3 \mathrm{~Hz} / \mathrm{s}$, hence triggering islanding detection mechanism and subsequently the DG breaker is tripped.

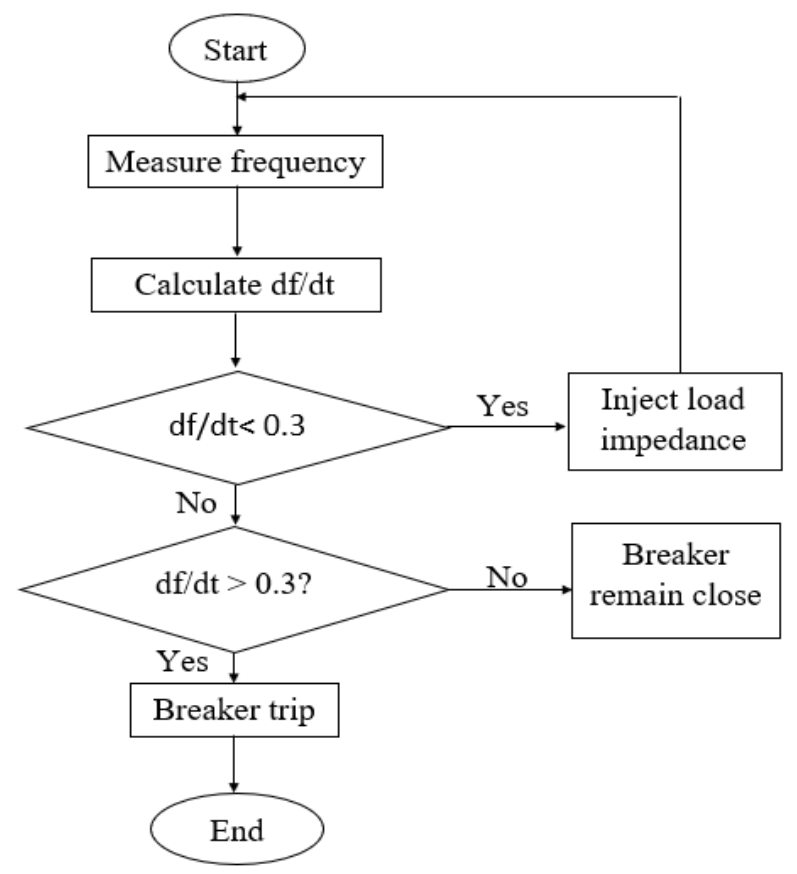

Figure 3. Flow chart of the proposed islanding detection method

Table 1. Analysis of the islanding detection on different range of $\Delta \mathrm{P}$ for various load values

\begin{tabular}{cccc}
\hline Range of $\Delta \mathrm{P}(\mathrm{kW})$ & Load $(\mathrm{kW})$ & Detect Islanding & Preferable \\
\hline $90-270$ & $150 \mathrm{~kW}$ & $\times$ & \\
& $330 \mathrm{~kW}$ & $\times$ & Prefer \\
& $540 \mathrm{~kW}$ & $\checkmark$ & \\
$280-430$ & $150 \mathrm{~kW}$ & $\times$ & Prefer \\
& $330 \mathrm{~kW}$ & $\checkmark$ & \\
& $540 \mathrm{~kW}$ & $\checkmark$ & Prefer \\
$440-540$ & $150 \mathrm{~kW}$ & $\checkmark$ & \\
& $330 \mathrm{~kW}$ & $\checkmark$ & \\
& $540 \mathrm{~kW}$ & $\checkmark$ & \\
& & &
\end{tabular}

\subsection{Test network}

The test system shown in Figure 4 was modelled using PSCAD software. The 7-bus system operates at $50 \mathrm{~Hz}, 33 \mathrm{kV}$, and includes a $100 \mathrm{MVA}$ generator as main supply. As shown in the Figure 4, there are two step-down transformers of $33 / 11 \mathrm{kV}$ and $11 / 3.3 \mathrm{kV}$ rated at 20MVA and 2MVA respectively. The 2MVA 
transformer is placed at the end of the distribution line where DG is located. The DG is modelled as a hydro turbine generator rated at 2 MVA. The loads connected to the system are static loads.

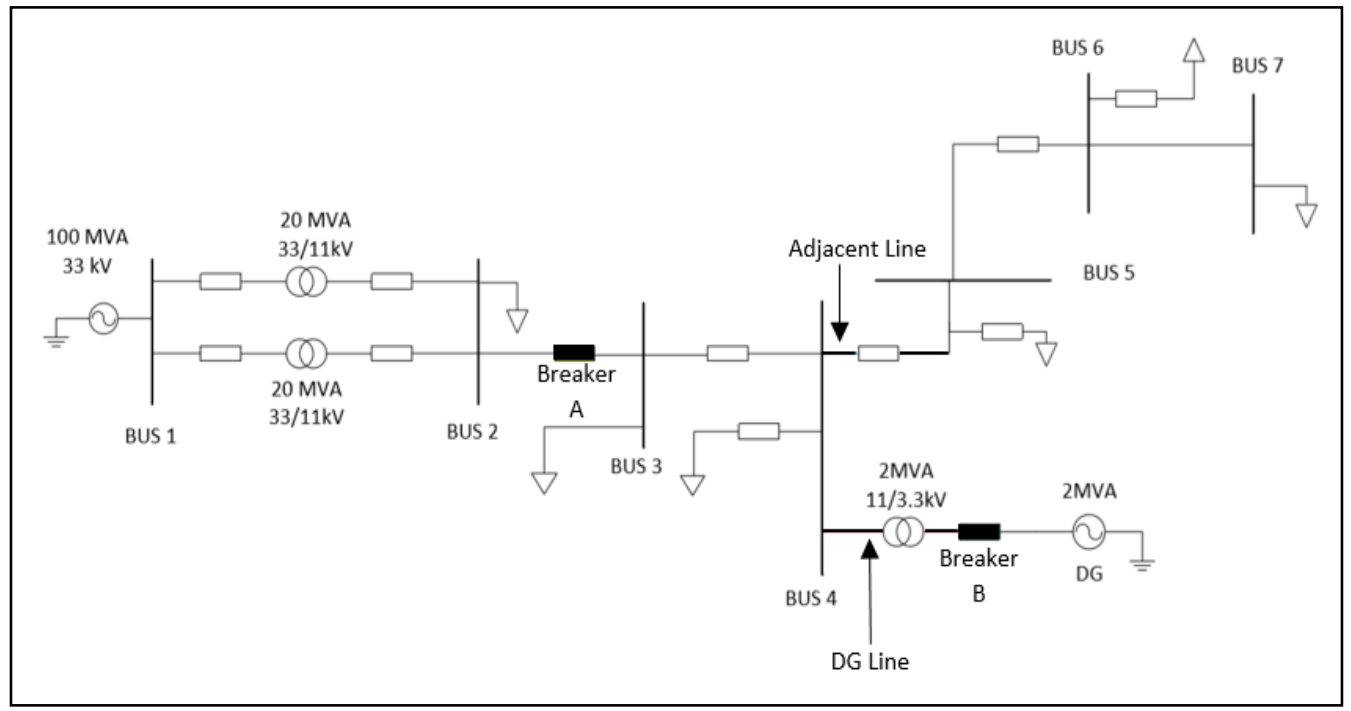

Figure 4. 7-bus test system

\section{RESULT AND ANALYSIS}

In order to evaluate the effectiveness of the proposed method, three case studies are simulated based on the 7-bus test system. The three case studies are:

- Case 1: Loss of main

- Case 2: Various fault at line connected to DG (DG Line)

- Case 3: Various fault at line adjacent to DG at line 4-5

The faults considered in this study are single line to ground fault, line to line to ground fault, and three phase fault. Case 1 which is loss of main, a signal is sent to open breaker A to disconnect the main supply at $t=10$ seconds. Case 2, three different types of faults are applied at line connected to DG as indicated in Figure 4. As for case 3, three different types of faults are applied at adjacent line (line 4-5) as indicated in Figure 4. Results for the three case studies are tabulated in Table 2.

Table 2. Breaker trip status for all three cases

\begin{tabular}{clc}
\hline Cases & \multicolumn{1}{c}{ Type of Events } & Breaker B Condition \\
\hline 1 & Loss of main & TRIP \\
2 & Single line to ground fault & TRIP \\
& Line to line to ground fault & TRIP \\
& Three phase faults & TRIP \\
3 & Single line to ground fault & NOT TRIP \\
& Line to line to ground fault & NOT TRIP \\
& Three phase faults & NOT TRIP \\
\hline
\end{tabular}

\subsection{Loss of main}

The system frequency immediately increases in response to the disconnection of main grid from the distribution network. Based on Figure 5, the frequency of DG increases until it hits $71 \mathrm{~Hz}$ then gradually drops to $30 \mathrm{~Hz}$. The frequency increment contributes to the increment of the ROCOF value. As can be seen in Figure 6 , the ROCOF reading at $\mathrm{t}=10$ seconds exceeds the ROCOF threshold which has been set at $0.3 \mathrm{~Hz} / \mathrm{s}$. As a result, a signal is sent to trip the breaker B. The islanding detection mechanism verifies that loss of main is islanding scenario and proceeds to trip breaker B causing the DG to shut down. The change of active power due to the islanding caused the frequency drops and unstable. Only passive method works for this case since the ROCOF value is greater than the threshold value. The high value of frequency and df/dt is due to a large power imbalance between generation and load the moment system is disconnected from the main. 


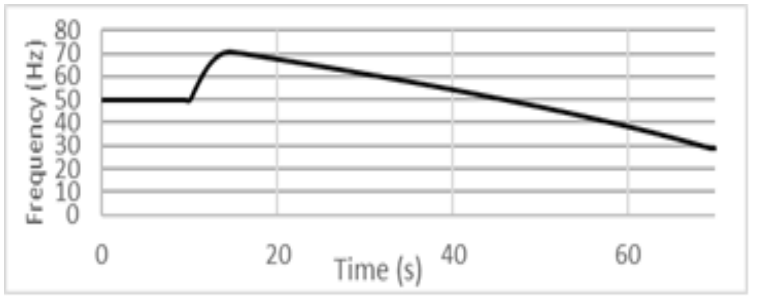

Figure 5. Frequency of DG for loss of main

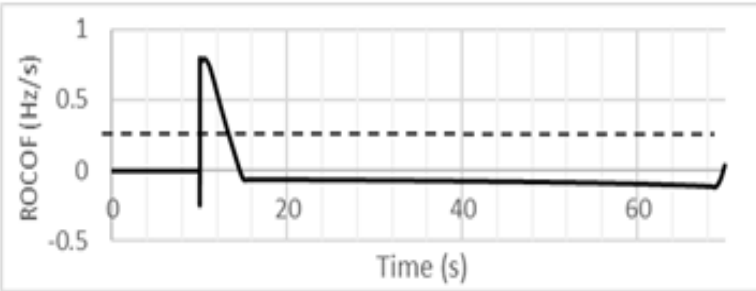

Figure 6. ROCOF measurement for loss of main

\subsection{Fault at DG line}

As mentioned earlier, three types of faults are simulated which are three phase fault, single line to ground fault, and line to line to ground fault. The fault is simulated at $\mathrm{t}=10$ seconds with 0.05 seconds of fault duration. For all type of faults, the reading of ROCOF exceeds the ROCOF's threshold value which causes breaker B to trip. Figures 7 and 8 shows the frequency response and ROCOF value respectively when a three-phase fault is applied to the system. Eventhough the fault duration is very short, huge impact to the system frequency can be seen following the fault. The response is almost similar to the response due to loss of main. The hybrid module manages to successfully detect the islanding scenario due to the fault location location is near to DG which contributes to the high ROCOF value.

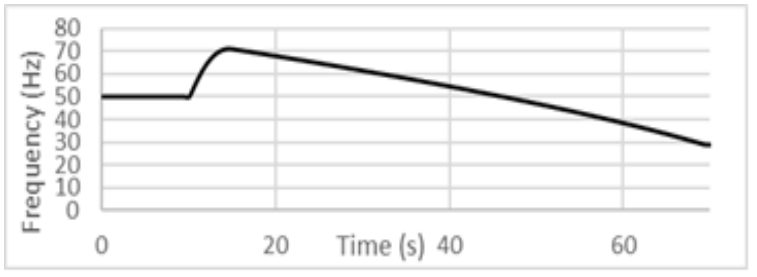

Figure 7. Frequency of DG for three phase fault

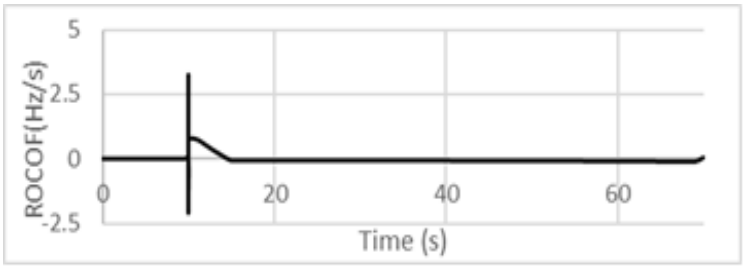

Figure 8. ROCOF measurement for three phase fault

\subsection{Fault at adjacent line (line 4-5)}

The adjacent line is located at the same bus with the DG line. The fault setting is set similar to case 2. Results show that breaker B does not trip for all three types of faults. The system frequency stays at $50 \mathrm{~Hz}$ following the fault as shown in Figure 9 (a). This causes the ROCOF to remain at zero value even after fault as shown in Figure 9 (b). The fault does not impact the system since it is applied at the load side as it does not interfere the power flow from power supply to DG.

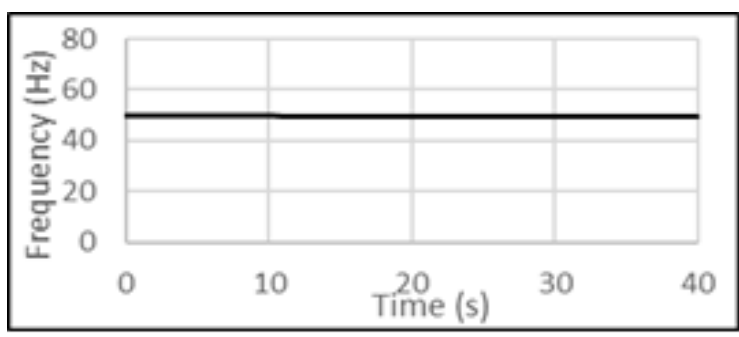

(a)

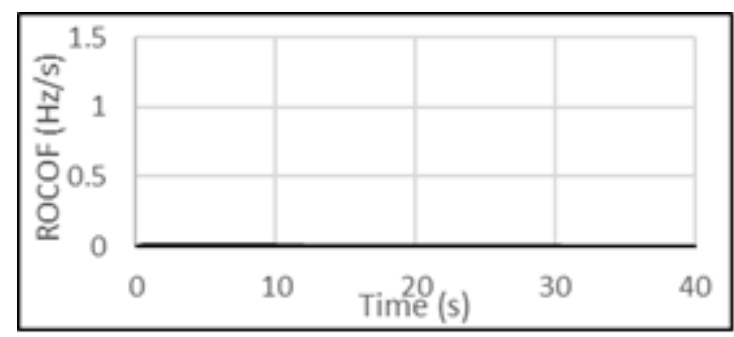

(b)

Figure 9. These figures are; (a) frequency, (b) ROCOF measurement for three phase faults at adjacent line1

\subsection{Comparative analysis}

Comparative analysis is carried out to analyse the advantage of having an active method in the proposed hybrid method. Simulation is performed for case 1 by using two different detection method: 1 ) passive method and 2) hybrid method module. The simulation is carried out for a small value of power mismatch, $\triangle \mathrm{P}$. Based on results shown in Figure 10, the reading of ROCOF for passive method does not even 
reach the threshold value since $\Delta \mathrm{P}$ is small. However, with the proposed hybrid method which combines passive and active method, the injection of load impedance from active method pushes the reading of ROCOF to reach the threshold value. As a result, the proposed method able to detect islanding for a small value of power imbalance as recorded in Table 3. This proves that the hybrid detection method gives better performance than passive method in detecting islanding event. Moreover, non-detection zone (NDZ), which is one of the most important criteria for islanding detection method is also assessed in identifying the area that both methods fail to detect islanding scenario. Rigorous testing is carried out to identify an accurate NDZ for both methods. The NDZ shown in Figure 11 obviously differentiate the accuracy of detection for both methods where the hybrid method has a smaller NDZ compared to the passive method. The result indicates that more islanding events can be detected by hybrid method compared to passive method, thus increasing the islanding detection reliability. In terms of detection time, the proposed hybrid method would detect islanding event in $35 \mathrm{~ms}$ and $70 \mathrm{~ms}$ for passive and hybrid method respectively. This indicates that the proposed method is better compared to other methods listed in Table 4. However, in real world application, the time taken may vary accordingly depending on the signal and communication delay.

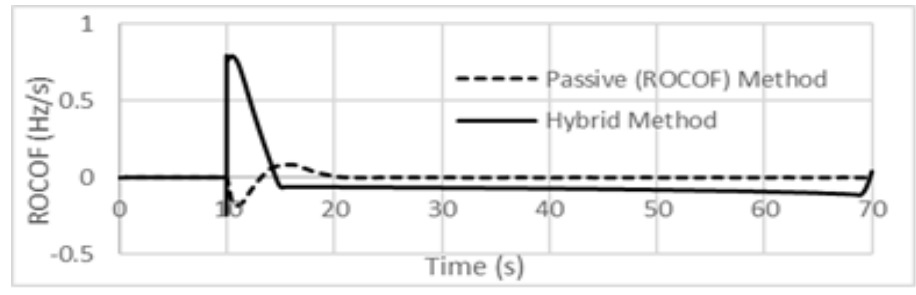

Figure 10. Comparison of ROCOF between hybrid method and passive method

Table 3. Result of loss of main with hybrid and passive method

\begin{tabular}{ccl}
\hline \multicolumn{2}{c}{ Cases } & Breaker B Condition \\
\hline Loss of main & Hybrid Method & TRIP \\
& Passive Method & NOT TRIP \\
\hline
\end{tabular}

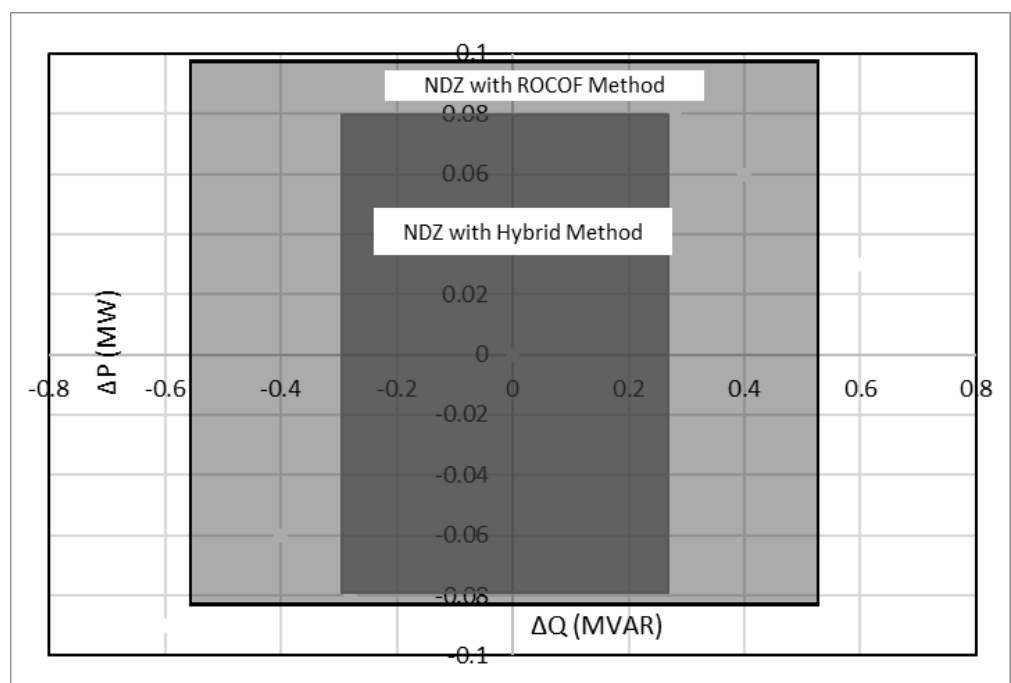

Figure 11. NDZ for ROCOF and hybrid methods

Table 4. Comparative analysis on islanding detection time

\begin{tabular}{lc}
\hline \multicolumn{1}{c}{ Detection Method } & Detection time (ms) \\
\hline Undervoltage block function [11] & 136.2 \\
Voltage Unbalance and Total Harmonic Distortion of Current [8] & 129 \\
Rate of Change of Exciter Voltage with Circuit Breaker Switching Strategy [29] & 100 (passive) \\
& 300 (hybrid) \\
Proposed method & 35 (passive) \\
\end{tabular}




\section{CONCLUSION}

This paper presents a hybrid islanding detection method by using the rate of change of frequency (ROCOF) and the injection of load impedance. Several case studies have been simulated on the test distribution system to assess the effectiveness of the proposed method. Results proved that the method effectively detected all event that could result in islanding. Comparison studies including the NDZ assessment with the passive method further validated the islanding detection performance of the hybrid method.

\section{ACKNOWLEDGEMENTS}

This work is supported by the Ministry of Higher Education and Universiti Teknologi MARA, Malaysia under FRGS research grant (Grant Code: 600-IRMI/FRGS 5/3(090/2019)).

\section{REFERENCES}

[1] J. R. Reddy, A. Pandian, R. Dhanasekharan, Ch. R. Reddy, B. P. Lakshmi, "Islanding detection of integrated distributed generation with advanced controller," Indonesian Journal of Electrical Engineering and Computer Science, vol. 17, no. 3, pp. 1626-1631, 2020, doi: 10.11591/ijeecs.v17.i3.pp1626-1631.

[2] S. Raza, H. Amjad, M. Umer and A. Khalid, "Analysis of power system parameters for islanding detection using wavelet transform," Indonesian Journal of Electrical Engineering and Computer Science, vol. 17, no. 3, pp. 11841193, 2020, doi: 10.11591/ijeecs.v17.i3.pp1184-1193.

[3] J. A. Laghari, H. Mokhlis, M. Karimi, A. H. A. Bakar, and H. Mohamad, "Computational Intelligence based techniques for islanding detection of distributed generation in distribution network: A review," Energy Conversion and Management, vol. 88, pp. 139-152, 2014, doi: 10.1016/j.enconman.2014.08.024.

[4] A. Sharma and R. Sunitha, "Unintentional islanding detection in microgrid," International Conference on Energy, Communication, Data Analytics and Soft Computing ICECDS, 2017, pp. 2519-2523, doi: 10.1109/ICECDS.2017.8389907.

[5] J. R. Reddy and A. Pandian, "Improved ROCOF relay for islanding detection of solar distributed generation," Indonesian Journal of Electrical Engineering and Computer Science, vol. 14, no. 3, pp. 1105-1113, 2019, doi: 10.11591/ijeecs.v14.i3.pp1105-1113.

[6] S. Nikolovski, H. R. Baghaee and D. Mlakić, "Islanding Detection of Synchronous Generator-Based DGs using Rate of Change of Reactive Power," EEE Systems Journal, vol. 13, no. 4, pp. 4344-4354, 2019, doi: 10.1109/JSYST.2018.2889981.

[7] S. K. Salman, D. J. King and G. Weller, "New loss of mains detection algorithm for embedded generation using rate of change of voltage and changes in power factors," Seventh International Conference on Developments in Power System Protection (IEE), 2001, pp. 82-85, doi: 10.1049/cp:20010105.

[8] Sung-Il Jang and Kwang-Ho Kim, "An islanding detection method for distributed generations using voltage unbalance and total harmonic distortion of current," IEEE Transactions on Power Delivery, vol. 19, no. 2, pp. 745752, April 2004, doi: 10.1109/TPWRD.2003.822964.

[9] Sung-Il Jang and Kwang-Ho Kim, "Development of a logical rule-based islanding detection method for distributed resources," IEEE Power Engineering Society Winter Meeting. Conference Proceedings (Cat. No.02CH37309), 2002, pp. 800-806 vol.2, doi: 10.1109/PESW.2002.985117.

[10] H. Abdi, A. Rostami, and N. Rezaei, "A Novel Passive Islanding Detection Scheme for Synchronous-type DG using Load Angle and Mechanical Power Parameters,” Electric Power Systems Research, vol. 192, p. 106968, 2021, doi: https://doi.org/10.1016/j.epsr.2020.106968.

[11] D. Motter and J. C. M. Vieira, "Improving the islanding detection performance of passive protection by using the undervoltage block function," Electric Power Systems Research, vol. 184, p. 106293, 2020, doi: 10.1016/j.epsr.2020.106293.

[12] S. Raza, T. ur Rahman, M. Saeed, and S. Jameel, "Performance analysis of power system parameters for islanding detection using mathematical morphology," Ain Shams Engineering Journal, vol. 12, no. 1, pp. 517-527, 2021, doi: $/ 10.1016 / j$.asej.2020.07.023.

[13] A. M. I. Mohamad and Y. A. I. Mohamed, "Impedance-Based Analysis and Stabilization of Active DC Distribution Systems With Positive Feedback Islanding Detection Schemes," IEEE Transactions on Power Electronics, vol. 33, no. 11, pp. 9902-9922, 2018, doi: 10.1109/TPEL.2018.2790945.

[14] W. J. Chiang, H. L. Jou, and J. C. Wu, "Active islanding detection method for inverter-based distribution generation power system," International Journal of Electrical Power \& Energy Systems, vol. 42, no. 1, pp. 158166, 2012, doi: 10.1016/j.ijepes.2012.03.038.

[15] A. Samui and S. R. Samantaray, "An active islanding detection scheme for inverter-based DG with frequency dependent ZIP-Exponential static load model," International Journal of Electrical Power \& Energy Systems, vol. 78, pp. 41-50, 2016, doi: 10.1016/j.ijepes.2015.11.054.

[16] B. Wen, D. Boroyevich, R. Burgos, Z. Shen and P. Mattavelli, "Impedance-Based Analysis of Active Frequency Drift Islanding Detection for Grid-Tied Inverter System," IEEE Transactions on Industry Applications, vol. 52, no. 1, pp. 332-341, 2016, doi: 10.1109/TIA.2015.2480847. 
[17] S. Murugesan, V. Murali and S. A. Daniel, "Hybrid Analyzing Technique for Active Islanding Detection Based on d-Axis Current Injection," IEEE Systems Journal, vol. 12, no. 4, pp. 3608-3617, 2018, doi: 10.1109/JSYST.2017.2730364.

[18] R. Bekhradian, M. Davarpanah and M. Sanaye-Pasand, "Novel Approach for Secure Islanding Detection in Synchronous Generator Based Microgrids," IEEE Transactions on Power Delivery, vol. 34, no. 2, pp. 457-466, 2019, doi: 10.1109/TPWRD.2018.2869300.

[19] D. Reigosa, F. Briz, C. Blanco, P. García and J. Manuel Guerrero, "Active Islanding Detection for Multiple Parallel-Connected Inverter-Based Distributed Generators Using High-Frequency Signal Injection," IEEE Transactions on Power Electronics, vol. 29, no. 3, pp. 1192-1199, March 2014, doi: 10.1109/TPEL.2013.2263845.

[20] H. Mohamad, A. N. Ab Salam, N. M. Razali, N. A. Salim, and Z. M. Yasin, "A New Islanding Detection Technique Based on Passive Parameter using a Combination of Artificial Neural Network and Evolutionary Programming Algorithm," Journal of Electrical and Electronic Systems Research, vol. 18, pp. 1-8, 2021.

[21] D. Mlakić, H. R. Baghaee and S. Nikolovski, "A Novel ANFIS-Based Islanding Detection for Inverter-Interfaced Microgrids," IEEE Transactions on Smart Grid, vol. 10, no. 4, pp. 4411-4424, 2019, doi: 10.1109/TSG.2018.2859360.

[22] H. R. Baghaee, D. Mlakić, S. Nikolovski and T. Dragicević, "Support Vector Machine-Based Islanding and Grid Fault Detection in Active Distribution Networks," IEEE Journal of Emerging and Selected Topics in Power Electronics, vol. 8, no. 3, pp. 2385-2403, 2020, doi: 10.1109/JESTPE.2019.2916621.

[23] B. P. L. K. Suresh, P. Anusha, Sk. Najma, B. I. Rajkumar, Ch. Rami Reddy, "A passive islanding detection method for hybrid distributed generation system under balanced islanding," Indonesian Journal of Electrical Engineering and Computer Science, vol. 14, no. 1, pp. 9-19, 2019, doi: 10.11591/ijeecs.v14.i1.pp9-19.

[24] V. Menon and M. H. Nehrir, "A Hybrid Islanding Detection Technique Using Voltage Unbalance and Frequency Set Point," IEEE Transactions on Power Systems, vol. 22, no. 1, pp. 442-448, 2007, doi: 10.1109/TPWRS.2006.887892.

[25] P. Mahat, Z. Chen and B. Bak-Jensen, "A Hybrid Islanding Detection Technique Using Average Rate of Voltage Change and Real Power Shift," IEEE Transactions on Power Delivery, vol. 24, no. 2, pp. 764-771, April 2009, doi: 10.1109/TPWRD.2009.2013376.

[26] M. Mohiti, Z. Mahmoodzadeh and M. Vakilian, "A hybrid micro grid islanding detection method," 13th International Conference on Environment and Electrical Engineering (EEEIC), 2013, pp. 342-347, doi: 10.1109/EEEIC-2.2013.6737933.

[27] R. Zamani, M. E. Hamedani Golshan, H. Haes Alhelou, and N. Hatziargyriou, "A novel hybrid islanding detection method using dynamic characteristics of synchronous generator and signal processing technique," Electric Power Systems Research, vol. 175, p. 105911, 2019, doi: 10.1016/j.epsr.2019.105911.

[28] G. Wang, F. Gao, J. Liu, Q. Li and Y. Zhao, "Design consideration and performance analysis of a hybrid islanding detection method combining voltage unbalance/total harmonic distortion and bilateral reactive power variation," CPSS Transactions on Power Electronics and Applications, vol. 5, no. 1, pp. 86-100, 2020, doi: 10.24295/CPSSTPEA.2020.00008.

[29] A. Rostami, A. Jalilian, M. T. Hagh, K. M. Muttaqi and J. Olamaei, "Islanding Detection of Distributed Generation Based on Rate of Change of Exciter Voltage With Circuit Breaker Switching Strategy," IEEE Transactions on Industry Applications, vol. 55, no. 1, pp. 954-963, 2019, doi: 10.1109/TIA.2018.2868547.

[30] S. D. Kermany, M. Joorabian, S. Deilami and M. A. S. Masoum, "Hybrid Islanding Detection in Microgrid With Multiple Connection Points to Smart Grids Using Fuzzy-Neural Network," IEEE Transactions on Power Systems, vol. 32, no. 4, pp. 2640-2651, 2017, doi: 10.1109/TPWRS.2016.2617344.

\section{BIOGRAPHIES OF AUTHORS}

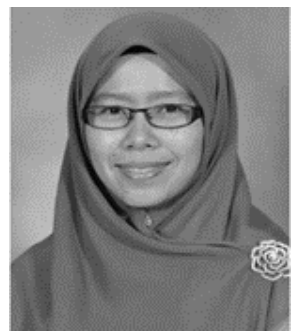

Hasmaini Mohamad received the B.Eng., M.Eng., and Ph.D. degrees from the University of Malaya, in 1999, 2004, and 2013, respectively. She started her career as a lecturer in Universiti Teknologi MARA in 2003 where currently she is an Associate Professor at the School of Electrical Engineering, College of Engineering. Apart from that, she has published more than 50 journal papers including high impact ISI journals and 20 conference papers. Her major research interest includes islanding operation of distributed generation, hydro generation, load sharing technique, and load shedding scheme.

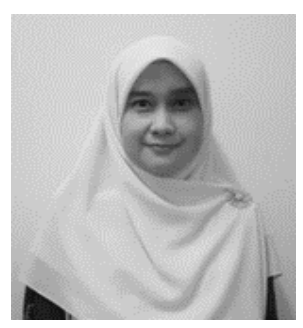

Zuhaila Mat Yasin graduated from Universiti Sains Malaysia with honours degree in Electrical and Electronics Engineering in 1998. She obtained her MSc degree in 2008 and PhD degree in 2015 from Universiti Teknologi MARA. She is currently a senior lecturer at Universiti Teknologi MARA. Her research interest includes power system operation, optimization, distributed generation, Artificial Intelligence and smart grid system. 

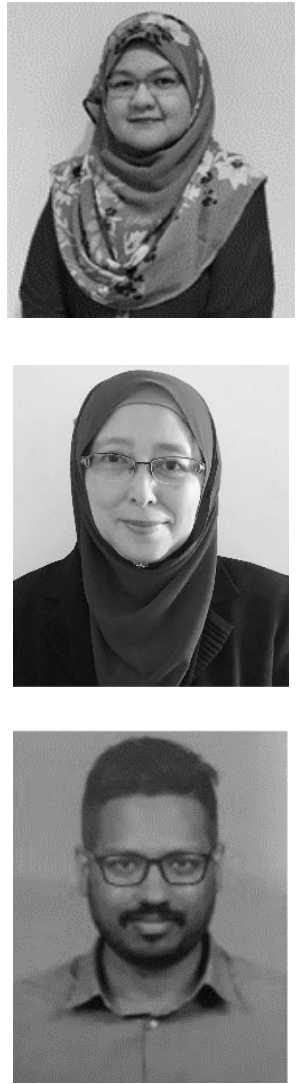

Nur Ashida Salim received her $\mathrm{PhD}$ in Electrical Engineering from Universiti Teknologi MARA in 2015, Master in Engineering (Power System \& Electrical Energy) from Universiti Malaya in 2006 and Bachelor in Electrical Engineering (Hons.) from Universiti Teknologi MARA in 2003. She is currently an Associate Professor at the School of Electrical Engineering, College of Engineering Universiti Teknologi MARA. Her research includes power system reliability, power system planning, power system stability, power system asset management and other related areas. To date, she has published more than 40 journal articles and many proceeding papers.

Bibi Norasiqin Sheikh Rahimullah obtained her MSC in Electrical Power Engineering from University of Strathclyde, UK in 1992. She is currently attached with College of Engineering, Universiti Teknologi MARA, Shah Alam, Selangor, Malaysia as an Associate Professor. She has authored and co-authored various proceeding and journal papers in electrical engineering and education field.

Kanendra Naidu received the master's and Ph.D. degrees in electrical engineering from the University of Malaya, in 2011 and 2015, respectively. He is currently a Senior Lecturer with the Universiti Teknologi MARA (UiTM), Shah Alam. His research interest includes electrical engineering specializing in the implementation of artificial intelligence in power systems. He also has strong working experience in a variety of evolutionary and swarm-based optimization techniques, graph theory, wavelet transform, and artificial neural networks. 